\title{
Chronic Kidney Disease in an Electronic Health Record Problem List: Quality of Care, ESRD, and Mortality
}

\author{
Stacey E. Jolly ${ }^{a}$ Sankar D. Navaneethan $^{b}$ Jesse D. Schold ${ }^{b, c}$ Susana Arrigain ${ }^{c}$ \\ John W. Sharp ${ }^{c}$ Anil K. Jain ${ }^{\text {a,d }}$ Martin J. Schreiber ${ }^{b}$ James F. Simon ${ }^{b}$ \\ Joseph V. Nally ${ }^{b}$ \\ ${ }^{a}$ Department of General Internal Medicine, Medicine Institute, ${ }^{b}$ Department of Nephrology and Hypertension, \\ Glickman Urological and Kidney Institute, 'Department of Quantitative Health Sciences, Cleveland Clinic, and \\ dExplorys, Cleveland, Ohio, USA
}

\section{Key Words}

Chronic kidney disease · Awareness · Quality · End-stage renal disease $\cdot$ Mortality

\begin{abstract}
Background: Whether chronic kidney disease (CKD) recognition in an electronic health record (EHR) problem list improves processes of care or clinical outcomes of end-stage renal disease (ESRD) and death is unclear. Methods: We identified patients who had at least 1 year of follow-up (2005$2009)$ in our EHR-based CKD registry $(n=25,742)$. CKD recognition was defined by having ICD-9 codes for CKD, diabetic kidney disease, or hypertensive kidney disease in the problem list. We calculated proportions of patients with and without CKD recognition and examined differences by demographics, clinical factors, and development of ESRD or mortality. We evaluated differences in the proportion of patients with CKD-specific laboratory results checked before and after recognition among cases and propensity-matched controls. Results: Only $11 \%(n=2,735)$ had CKD recognition in the problem list and they were younger (68 vs. 71 years), a higher proportion were male (61 vs. $37 \%$ ) and AfricanAmerican (21 vs. $10 \%$ ) compared to those unrecognized. CKD-specific laboratory results for patients with estimated
\end{abstract}

glomerular filtration rate (eGFR) 30-59 including intact parathyroid hormone ( 23 vs. $6 \%$ ), vitamin D ( 22 vs. $18 \%$ ), phosphorus ( 29 vs. $7 \%$ ), and a urine check for proteinuria ( 55 vs. $36 \%$ ) were significantly more likely to be done among those with CKD recognition (all $p<0.05$ ). Similar results were found for eGFR $<30$ except for proteinuria and in our propensity score-matched control analysis. There was no independent association of CKD recognition with ESRD or mortality. Conclusions: CKD recognition in the EHR problem list was low, but translated into more CKD-specific processes of care; however ESRD or mortality were not affected.

ㄷ) 2014 S. Karger AG, Basel

\section{Introduction}

Chronic kidney disease (CKD) awareness is low among patients and providers [1]. This is of concern because $\mathrm{CKD}$ is increasing [2] and may progress to advanced CKD or end-stage renal disease (ESRD) requiring costly dialysis and/or transplantation care [3]. CKD is a public

Portions of this article were presented as a poster (TH-PO341) at ASN Renal Week 2011, Philadelphia, Pa., USA.

\section{KARGER}

E-Mail karger@karger.com

www.karger.com/ajn
(C) 2014 S. Karger AG, Base

0250-8095/14/0394-0288\$39.50/0
Stacey E. Jolly, MD, MAS

Department of General Internal Medicine

Cleveland Clinic Medicine Institute, Cleveland Clinic

9500 Euclid Avenue, G10, Cleveland, OH 44195 (USA)

E-Mail jollys@ccf.org 
health concern given its association with comorbid conditions, such as diabetes, hypertension, cardiovascular disease, and increased risk of death [3-8].

The National Kidney Foundation published Kidney Disease Outcome Quality Initiative (KDOQI) guidelines to provide a framework for the diagnosis and clinical management of patients with CKD [3], and additional guidelines to address the global impact of CKD have been developed [9]. National efforts to increase recognition of CKD have been underway with the hope they will lead to wider adoption of evidence-based CKD care and, accordingly, better health outcomes in patients with CKD.

An expectation is that with expansion in electronic health record (EHR) usage, which has been propelled by the passage of legislation, the Health Information Technology for Economic and Clinical Health (HITECH) Act in 2009 and meaningful use incentives from Centers for Medicare and Medicaid Services [10], quality of care will improve. Studies have shown a benefit of EHRs on quality of care and increased adherence to guideline-based care for some health conditions [11-13]. However, while processes of care have been shown to improve with EHRs, other quality measures are not always improved and clinical outcomes may not change [14-17]. Nonetheless, EHRs are or will soon be used at most institutions and so their evaluation and impact on clinical medicine is important.

Our objectives were to determine CKD recognition prevalence in an EHR problem list among a large CKD cohort, examine whether differences in processes of care, development of ESRD or mortality were associated with $\mathrm{CKD}$ recognition, and investigate the independent effect of CKD recognition on processes of care.

\section{Methods}

\section{CCF CKD Registry}

The development and validation of our EHR-based CKD registry has been described [18]. Our parent CKD registry included 49,663 patients who had two estimated glomerular filtration rate (eGFR) readings $<60 \mathrm{ml} / \mathrm{min} / 1.73 \mathrm{~m}^{2}$ using the 4 -variable Modification of Diet in Renal Disease (MDRD) equation more than 90 days apart between January 1, 2005 and September 15, 2009. We chose the MDRD equation because it was used for automated eGFR reporting within the EHR of our health system during the time period studied, so available to clinicians.

\section{Study Group}

We included patients from the parent CKD registry with at least 1 year follow-up in our registry with a Cleveland Clinic primary care provider (PCP) listed in the EHR or had seen a Cleve- land Clinic nephrologist up to 1 year after the confirmatory eGFR for CKD. We excluded patients who developed ESRD during the first year of follow-up.

\section{Renal Function}

All creatinine measurements were performed by the modified kinetic Jaffe reaction, using a Hitachi 747-200 Chemistry Analyzer (1996-2001) or a Hitachi D 2400 Modular Chemistry Analyzer thereafter (Roche Diagnostics, Indianapolis, Ind., USA).

\section{CKD Recognition}

CKD recognition was defined by having at least one noted diagnosis of CKD in the EHR problem list. We used the following ICD9 codes: chronic kidney disease $(585,585.1,585.2,585.3,585.4$, $585.5,585.6,585.9)$, diabetic nephropathy $(250.4,250.40,250.41$, $250.42,250.43$ ), unspecified renal failure (586), and hypertensive kidney disease (403). CKD recognition could occur as late as 365 days after the date of the second eGFR $<60 \mathrm{ml} / \mathrm{min} / 1.73 \mathrm{~m}^{2}$, allowing up to 1 year to have CKD be put into the EHR problem list. Any healthcare provider can update the EHR problem list and while our EHR is not linked to any CKD-specific decision support, there are health maintenance reminders or flags for things such as having an annual urine albumin check among patients with diabetes. Conversely, the EHR problem list might have contained CKD prior to the second confirmatory eGFR $<60 \mathrm{ml} / \mathrm{min} / 1.73 \mathrm{~m}^{2}$. For the analysis on change in processes of care pre-/post-recognition only, we selected patients with no recognition prior to second confirmatory eGFR $<60$, and looked for the first instance of recognition during follow-up, even beyond 1 year post-confirmatory eGFR.

\section{Demographics and Comorbid Conditions}

Demographics were extracted from the EHR. We present data for those patients identified as Caucasian, African-American, or neither of those categories and for the purpose of our study are categorized as Other. Insurance was categorized as Medicare, Medicaid, and Other which includes any non-Medicare/Medicaid health insurance. Diabetes, hypertension, hyperlipidemia, and other comorbid conditions were identified using validated ICD-9 codes and augmented in some cases with medications, vitals and laboratory results [18].

\section{Outcome Measures}

Processes of Care/Quality of Care

Nephrology visit was defined as a completed office visit with a nephrology provider within 12 months of entry into the CKD registry. $\mathrm{ACE} / \mathrm{ARB}$, statin and metformin use were extracted from the EHR using the noted start and end dates to ascertain the period of use and including any medication active within 12 months of entry into the CKD registry. Metformin use was only evaluated for diabetic CKD patients.

We chose processes of care that are more CKD-specific to assess what impact CKD recognition may have on guideline concordant care. We looked at each process of care individually and then as a composite outcome. We assessed whether patients had an outpatient intact parathyroid hormone (iPTH), $25[\mathrm{OH}]$ vitamin $\mathrm{D}$, or phosphorus level measured, and any urine test to check for proteinuria or albuminuria within 12 months of entry into the CKD registry. The urine test to check for proteinuria included any of the following: urine albumin, urine microalbumin, urine albumin/ creatinine ratio, and urine microalbumin/creatinine ratio. 
Development of End-Stage Renal Disease

We obtained United States Renal Data System (USRDS) data up to September 15, 2009. Our patients that were not observed to develop ESRD during follow-up were censored on September 15, 2009.

\section{All-Cause Mortality}

The CKD registry was linked to the Social Security Death Index. For mortality, analysis patients were followed from their date of inclusion in the registry until death or censorship on October $31,2011$.

\section{Statistical Analysis}

We calculated the proportion of patients who had CKD recognized in the EHR problem list. Next we compared demographics, insurance at the time of data extraction, the average number of office visits per year of follow-up in the EHR, and eGFR and comorbidities at the time of confirmatory eGFR $<60$, between those patients with and without CKD recognition using $\chi^{2}$ and $t$ tests for categorical and continuous variables respectively. Additionally, we calculated the proportion of patients who had CKD recognized in the EHR problem list by CKD stage, gender, and race. Then we compared the proportion of processes of care for patients with and without recognition in the year following confirmatory eGFR for CKD using $\chi^{2}$ tests.

To assess independent associations, we fit a logistic regression model with $\mathrm{CKD}$ recognition as the outcome including the following covariates selected a priori: age, sex, race, insurance, eGFR, diabetes, hypertension, coronary artery disease, heart failure, hyperlipidemia and cerebrovascular disease. In separate models including the same variables previously mentioned and eGFR $<30$ instead of continuous eGFR, we tested two-way interaction between eGFR $<30$ versus eGFR $>30$ and each of the following: age, gender, race, diabetes, hypertension and cerebrovascular disease.

To evaluate whether CKD recognition was associated with development of ESRD and mortality, we fit separate Cox proportional hazard models for each of those outcomes with inception time being 365 days after the date of the second eGFR $<60 \mathrm{ml} /$ $\mathrm{min} / 1.73 \mathrm{~m}^{2}$. We adjusted for covariates defined at the time of model inception. We developed several models by incrementally adding covariates to understand the impact of these factors on time to ESRD and mortality. First we fit an unadjusted model and then adjusted for age, sex, and race. Next we added insurance, and then eGFR and the aforementioned co-morbidities. We did not have proteinuria data in all patients, however we conducted a sensitivity analysis fitting the full model plus proteinuria among the subset of patients with available data.

To evaluate whether patients who got CKD added to their EHR problem list had more processes of care after CKD recognition, we examined a subset of patients with $\mathrm{CKD}$ recognition occurring after the second confirmatory eGFR for CKD and who also had outpatient care starting at least 1 year prior to CKD recognition and ending at least 1 year after CKD recognition. To evaluate patients without CKD recognition as potential controls, we created a time point comparable to the recognition time, adding the average number of days to recognition to the date of confirmatory eGFR and checked for outpatient care 1 year before and 1 year after. Then we built a propensity score model of CKD recognition using the following variables: eGFR, age, African-American race, gender, average number of yearly visits, diabetes, coronary artery disease, congestive heart failure, cerebrovascular disease, and within the prior year had a nephrology visit, vitamin $\mathrm{D}, \mathrm{iPTH}$, phosphorus, and proteinuria checked. Patients were matched on propensity score with 0.1 caliper width by greedy matching [19]. We then evaluated the proportion of patients who had the CKD-specific processes of care individually and as a summary measure before and after CKD recognition (or analogous time if no recognition occurred) with McNemar's test separately for recognized and unrecognized patients.

For analyses we used Unix SAS version 9.2 (SAS Institute, Cary, N.C., USA) and for graphs we used R 2.12.2 (The R Foundation for Statistical Computing, Vienna, Austria). Greedy matching was done with the \%gmatch macro [19]. This study was approved by Cleveland Clinic Institutional Review Board.

\section{Results}

From our CKD registry of 49,663 patients, $54 \%$ ( $\mathrm{n}=$ 26,657 ) had at least 1 year of follow-up and a Cleveland Clinic PCP or nephrologist. However, 650 were excluded because they were missing an entry date for CKD in their problem list. Additionally, 265 patients developed ESRD within 1 year of confirmatory eGFR and were excluded. This left us with 25,742 patients who constituted our study population. Mean age was 70.7 years $(\mathrm{SD}=12.5)$, $40 \%$ were male, and $11 \%$ African-American. Strikingly, only $11 \%(\mathrm{n}=2,735)$ had CKD recognition.

Patients with CKD recognized were significantly younger, more likely to be male, African-American, and have more comorbidities (table 1; fig. 1). CKD recognition differed by stage of $\mathrm{CKD}$, with patients who had more advanced CKD being more likely to be recognized (table 1). Differences existed for CKD recognition by gender and race among CKD stages (fig. 1).

During the year following confirmatory eGFR for $\mathrm{CKD}$, patients with $\mathrm{CKD}$ recognition had more nephrology visits, more ACE/ARB and statin prescriptions, less inappropriate use of metformin among diabetics with $\mathrm{CKD}$, and more recommended laboratory results measured than those without $\mathrm{CKD}$ recognition, both among patients with eGFR $30-59$ and eGFR $<30$ (table 2).

Older age and higher eGFR were independently associated with significantly lower CKD recognition, while African-American race, diabetes, hypertension, and cerebrovascular disease were independently associated with significantly higher CKD recognition (table 3 ). We found significant interactions between eGFR $<30$ and gender, diabetes and hypertension. The interactions showed lower eGFR was significantly associated with higher odds of 
Fig. 1. CKD recognition in the EHR problem list by (a) gender and $(\mathbf{b})$ race stratified by eGFR $(n=25,742)$.

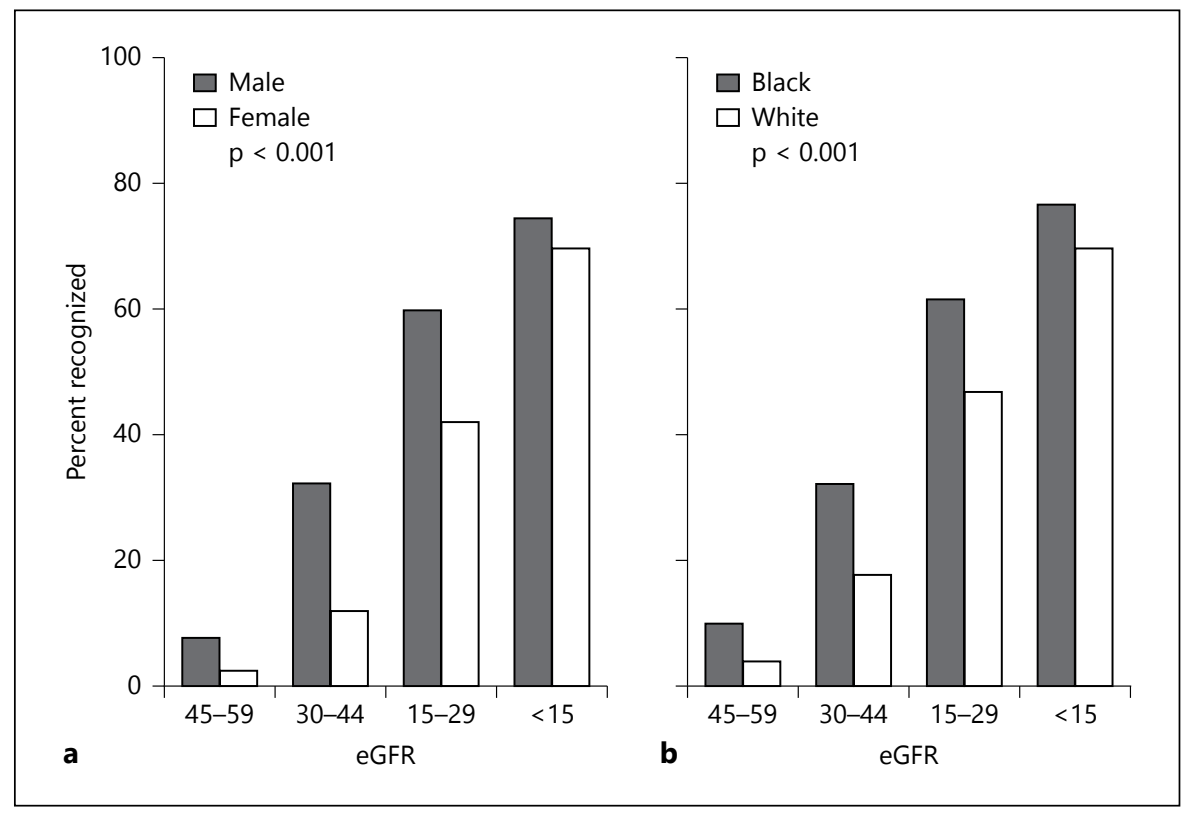

Table 1. Characteristics of those with and without CKD recognition in the EHR problem list

\begin{tabular}{|c|c|c|c|}
\hline Characteristic & $\begin{array}{l}\text { No recognition } \\
(\mathrm{n}=23,007)\end{array}$ & $\begin{array}{l}\text { CKD recognition } \\
(\mathrm{n}=2,735)\end{array}$ & $\mathrm{p}$ value $\mathrm{a}^{\mathrm{a}}$ \\
\hline Age, years, mean $\pm S D$ & $70.9 \pm 12.3$ & $68.4 \pm 13.8$ & $<0.001^{\mathrm{b}}$ \\
\hline Female, n (\%) & $14,424(62.7)$ & $1,069(39.1)$ & $<0.001$ \\
\hline Male, $\mathrm{n}(\%)$ & $8,583(37.3)$ & $1,666(60.9)$ & \\
\hline Race, n (\%) & & & $<0.001$ \\
\hline Caucasian & $20,424(88.8)$ & $2,098(76.7)$ & \\
\hline African-American & $2,227(9.7)$ & $583(21.3)$ & \\
\hline Other ${ }^{\mathrm{c}}$ & $356(1.5)$ & $54(2.0)$ & \\
\hline Insurance $^{\mathrm{d}}, \mathrm{n}(\%)$ & & & $<0.001$ \\
\hline Medicare & $17,462(77.3)$ & $2,066(77.6)$ & \\
\hline Medicaid & $131(0.58)$ & $27(1.0)$ & \\
\hline Other ${ }^{c}$ & $4,991(22.1)$ & $571(21.4)$ & \\
\hline Years of outpatient follow-up, mean \pm SD & $4.6 \pm 1.6$ & $4.5 \pm 1.8$ & 0.040 \\
\hline Office visits per year, mean \pm SD & $6.3 \pm 4.7$ & $7.7 \pm 5.7$ & $<0.001^{\mathrm{b}}$ \\
\hline eGFR & $50.1 \pm 8.6$ & $37.5 \pm 12.3$ & $<0.001^{\mathrm{b}}$ \\
\hline CKD stages & & & $<0.001$ \\
\hline CKD stage $3 \mathrm{a}$ & $17,680(76.8)$ & $833(30.5)$ & \\
\hline CKD stage $3 b$ & $4,572(19.9)$ & $1,101(40.3)$ & \\
\hline CKD stage 4 & $715(3.1)$ & $699(25.6)$ & \\
\hline CKD stage 5 & $40(0.17)$ & $102(3.7)$ & \\
\hline eGFR at 1 year post-confirmation & $52.6 \pm 11.7$ & $37.0 \pm 14.2$ & $<0.001^{\mathrm{b}}$ \\
\hline \multicolumn{4}{|l|}{ Comorbid conditions, $\mathrm{n}(\%)$} \\
\hline Hypertension, yes & $20,841(90.6)$ & $2,558(93.5)$ & $<0.001$ \\
\hline Coronary artery disease, yes & $4,317(18.8)$ & $683(25.0)$ & $<0.001$ \\
\hline Congestive heart failure, yes & $1,292(5.6)$ & $271(9.9)$ & $<0.001$ \\
\hline Hyperlipidemia, yes & $19,154(83.3)$ & $2,230(81.5)$ & 0.024 \\
\hline Cerebrovascular disease & $2,042(8.9)$ & $325(11.9)$ & $<0.001$ \\
\hline Diabetes, yes & $5,285(23.0)$ & $1,096(40.1)$ & $<0.001$ \\
\hline
\end{tabular}


Table 2. Processes of care measured within a year after confirmatory eGFR for CKD among those with and without CKD recognition in the EHR problem list stratified by eGFR level

\begin{tabular}{|c|c|c|c|c|}
\hline \multirow[t]{2}{*}{ Processes of care measures } & \multicolumn{2}{|l|}{ eGFR 30-59 } & \multicolumn{2}{|l|}{ eGFR $<30$} \\
\hline & $\begin{array}{l}\text { no } \\
(\mathrm{n}=22,252)\end{array}$ & $\begin{array}{l}\text { recognized } \\
(\mathrm{n}=1,934)\end{array}$ & $\begin{array}{l}\text { no } \\
(\mathrm{n}=755)\end{array}$ & $\begin{array}{l}\text { recognized } \\
(\mathrm{n}=801)\end{array}$ \\
\hline Nephrology office visit, n (\%) & $1,010(4.5)$ & $681(35.2)$ & $147(19.5)$ & $456(56.9)$ \\
\hline ACE/ARB, yes, n (\%) & $12,796(57.5)$ & $1,471(76.1)$ & $452(59.9)$ & $512(63.9)$ \\
\hline Statin, yes, n (\%) & $12,262(55.1)$ & $1,257(65.0)$ & $390(51.7)$ & $475(59.3)$ \\
\hline Metformin for diabetics, yes, $(\%)(n=6,476)$ & $818(16.1)$ & $88(11.2)$ & $7(3.3)$ & $<5(0.3)$ \\
\hline iPTH measured, yes, n (\%) & $1,227(5.5)$ & $442(22.9)$ & $136(18.0)$ & $398(49.7)$ \\
\hline Vitamin D measured, yes, n (\%) & $3,920(17.6)$ & $424(21.9)$ & $95(12.6)$ & $203(25.3)$ \\
\hline Phosphorus measured, yes, n (\%) & $1,618(7.3)$ & $561(29.0)$ & $189(25.0)$ & $450(56.2)$ \\
\hline Any proteinuria measured, yes, n (\%) & $8,035(36.1)$ & $1,063(55.0)$ & $340(45.0)$ & $376(46.9)$ \\
\hline
\end{tabular}

For patients with eGFR 30-59, all processes of care significantly different between patients with and without recognition, $\chi^{2} \mathrm{p}<0.001$. For patients with eGFR $<30$ nephrology visit, statin, $\mathrm{PTH}$, vitamin $\mathrm{D}$, phosphorus and metformin for diabetics significantly different between patients with and without recognition, $\chi^{2} \mathrm{p}<0.05$.

recognition in all groups but the strength of the association varied in different groups. The strength of association between gender and CKD recognition was lower in patients with GFR $<30$ (male vs. female: OR $1.93,95 \%$ CI $1.56,2.39$ ) than in patients with GFR $\geq 30$ (OR 3.03, 95\% CI 2.70, 3.33). Likewise, the associations between diabetes and hypertension and CKD recognition were lower in patients with GFR $<30$ than in GFR $\geq 30$ (respectively OR $1.33,95 \%$ CI $1.06-1.67$ vs. OR 1.93 , 95\% CI $1.74-2.14$ for diabetes, and OR $1.26,95 \%$ CI $1.04-1.52$ vs. OR $2.43,95 \%$ CI 1.65-3.57 for hypertension).

Among our study population, 4,638 (18\%) patients died. $21,068 / 25,742$ (82\%) had confirmatory eGFR before September 15, 2008 and were included in the ESRD model (to allow for CKD recognition up to 1 year postconfirmation in the ESRD model). Patients entered into the registry before September 15, 2008 were significantly older, more African-American, had lower eGFR, less hypertension, more $\mathrm{CAD}$, more $\mathrm{CHF}$, less hyperlipidemia, more CVD and more diabetes but the differences were mostly small. 416 (2\%) developed ESRD. The median mortality follow-up was 3.3 years and the median ESRD follow-up was 1.9 years. In Cox proportional hazards models, CKD recognition was significantly associated with higher hazard of mortality and ESRD in the unadjusted and partially adjusted models, but the association was not statistically significant for either outcome after adjustment for all covariates including eGFR and comorbidities (table 4). Similar results were found in the sensitivity analysis adjusted for proteinuria.
Table 3. Factors associated with $\mathrm{CKD}$ in the EHR problem list from multivariate analysis

\begin{tabular}{ll}
\hline Covariate & OR $(95 \% \mathrm{CI})$ \\
\hline Age per 10-year increase & $0.80(0.76,0.83)$ \\
Gender: male vs. female & $3.15(2.86,3.47)$ \\
Race (reference is Caucasian) & \\
$\quad$ African-American & $2.20(1.95,2.50)$ \\
$\quad$ Other & $1.22(0.88,1.71)$ \\
Insurance (reference is Medicare) & \\
$\quad$ Medicaid & $0.64(0.38,1.08)$ \\
$\quad$ Other & $0.85(0.74,0.97)$ \\
$\quad$ Missing & $0.97(0.71,1.32)$ \\
eGFR per 5-unit increase & $0.58(0.57,0.59)$ \\
Diabetes & $1.76(1.59,1.94)$ \\
Hypertension & $1.44(1.20,1.73)$ \\
Coronary artery disease & $1.05(0.94,1.18)$ \\
Heart failure & $0.99(0.84,1.17)$ \\
Hyperlipidemia & $0.93(0.82,1.06)$ \\
Cerebrovascular disease & $1.23(1.06,1.43)$ \\
\hline
\end{tabular}

\section{Propensity Score-Matched Control Analysis}

For cases, there were 2,587 patients who had CKD recognized for the first time at some point during follow-up and who also had care 1 year before and 1 year after recognition. For controls, there were 13,638 potential unrecognized patients with care 1 year before and 1 year after the time point equivalent to recognition. We were able to match $1,896 / 2,587(73 \%)$ on propensity score with 0.1 caliper width. All propensity-matched variables had stan- 
Table 4. Risk of dialysis or death with CKD recognition in the EHR problem list

\begin{tabular}{|c|c|c|c|c|}
\hline Model 1 - CKD recognition only & $12.7(10.4,15.5)$ & $<0.001$ & $1.53(1.41,1.66)$ & $<0.001$ \\
\hline Model 2 - including age, sex, race/ethnicity & $9.4(7.6,11.6)$ & $<0.001$ & $1.61(1.48,1.75)$ & $<0.001$ \\
\hline Model 3 - plus insurance & $9.0(7.3,11.1)$ & $<0.001$ & $1.61(1.49,1.75)$ & $<0.001$ \\
\hline Model 4 - plus eGFR and co-morbidities ${ }^{c}$ & $1.18(0.94,1.49)$ & 0.15 & $1.04(0.95,1.14)$ & 0.42 \\
\hline Model 5 - plus proteinuria ${ }^{\mathrm{d}}$ & $1.05(0.81,1.37)$ & 0.72 & $0.96(0.87,1.07)$ & 0.44 \\
\hline
\end{tabular}

Table 5. Processes of care pre- and post-CKD recognition in the EHR problem list propensity score-matched analysis

\begin{tabular}{|c|c|c|c|c|}
\hline \multirow[t]{2}{*}{ CKD process of care measurement } & \multicolumn{2}{|c|}{$\begin{array}{l}\text { CKD recognition in EHR problem list } \\
(\mathrm{n}=1,896)\end{array}$} & \multicolumn{2}{|c|}{$\begin{array}{l}\text { Propensity-matched controls } \\
(\mathrm{n}=1,896)\end{array}$} \\
\hline & pre & post & pre & post \\
\hline Nephrology office visit, n (\%) & $327(17.2)$ & $412(21.7)$ & $270(14.2)$ & $191(10.1)$ \\
\hline ACE/ARB, yes, n (\%) & $1,438(75.8)$ & $1,341(70.7)$ & $1,217(64.2)$ & $1,172(61.8)$ \\
\hline Statin, yes, $\mathrm{n}(\%)$ & $1,305(68.8)$ & $1,291(68.1)$ & $1,153(60.8)$ & $1,123(59.2)$ \\
\hline Phosphorus level checked, n (\%) & $297(15.7)$ & $562(29.6)$ & $278(14.7)$ & $224(11.8)$ \\
\hline Any proteinuria checked & $1,022(53.9)$ & $1,013(53.4)$ & $1,036(54.6)$ & $930(49.1)$ \\
\hline \multicolumn{5}{|l|}{ Summary measure (sum $0-4$ ) } \\
\hline None of the 4 labs checked, n (\%) & $679(35.8)$ & $624(32.9)$ & $664(35.0)$ & $753(39.7)$ \\
\hline Any 1 of the 4 labs checked, n (\%) & $726(38.3)$ & $526(27.7)$ & $771(40.7)$ & $701(37.0)$ \\
\hline Any 2 of the 4 labs checked, n (\%) & $301(15.9)$ & $294(15.5)$ & $282(14.9)$ & $296(15.6)$ \\
\hline
\end{tabular}

McNemar's test $\mathrm{p}<0.05$ for change pre/post in measurement of vitamin D, iPTH, phosphorus, nephrology visit and ACE/ARB among recognized patients. Among non-recognized iPTH, phosphorus, proteinuria, nephrology visits, ACE/ARB and statins $\mathrm{p}<0.05$.

dardized differences below $10 \%$ after the match. Only hypertension ( 89 vs. $92 \%, p<0.001)$ and nephrology visit in the prior year (17 vs. $14 \%, \mathrm{p}=0.01$ ) were slightly different. Age was similar between the patients whose CKD was recognized and the matched controls (70.4 \pm 12 vs. $71 \pm 12$ years, $\mathrm{p}=0.11$ ). Likewise, comparing patients in the CKD recognition group versus the matched controls, 52 vs. $54 \%$ were males $(\mathrm{p}=0.40), 14 \%$ were African-Americans in both groups $(\mathrm{p}=0.23)$, and $33 \%$ vs. $35 \%$ had diabetes $(\mathrm{p}=0.26)$. Table 5 shows the proportion that had ne- phrology visits, $\mathrm{ACE} / \mathrm{ARB}$, statins, and CKD-specific processes of care individually and as summary measures obtained in the year before recognition and after recognition for matched recognized and unrecognized patients. Nephrology visits went up among recognized patients after EHR recognition (to 21.7\%) while they decreased among non-recognized patients (to 10.1\%). Patients with CKD recognition in the EHR problem list had increased post-CKD recognition of CKD-specific processes of care compared to propensity score-matched controls. 


\section{Discussion}

Although documentation of CKD in the EHR problem list was low, recognition of CKD by providers was associated with increased CKD-specific processes of care and medication usage but ESRD and mortality rates were not affected. Males, African-Americans, and those with more advanced CKD were more likely to have CKD documented in the EHR problem list. We found an association of increased quality of care as defined by having had processes of care undertaken per current CKD guidelines among those that had CKD recognition compared to those who did not. This relationship held true for our subset of patients whom we did a propensity score-matched control analysis looking before and after CKD recognition among patients having CKD included in their EHR problem list or not.

Others have found under-documentation of CKD in the EHR [20-23]. Among a multispecialty group practice of 15 health centers, about $25 \%$ of the 12,000 patients with CKD had it listed in the problem list [22]. In an urban setting with a high-risk population, nearly $50 \%$ of the 300 patients with CKD had ICD-9 coding documentation [23]. Through chart review of nearly 900 patients with an eGFR $<60$ being cared for in rural practices, a study found less than $50 \%$ with documented CKD, even among those with high-risk conditions such as hypertension and diabetes [24]. Similar to our finding of increased recognition with advanced CKD, a PCP practice-based research network with nearly $35,000 \mathrm{CKD}$ patients found very low documentation of diagnosis among early CKD eGFR 45$59(<10 \%)$, but higher documentation among CKD eGFR 30-44 (54\%) and eGFR 15-29 (54\%) [25]. Unlike our study, they did not report processes of care nor ESRD or mortality rates.

Better problem list documentation has been associated with a higher quality of care and greater adherence to guidelines among patients with heart failure [26]. Likewise, meaningful use of EHRs was associated with significantly higher achievement and greater improvement in diabetes quality of care [13]. Documentation of CKD by ICD-9 coding has been shown to be associated with more statin or ACE/ARB use and less non-steroidal antiinflammatory use [20]. In contrast, under-documentation of patients with CKD led to less CKD guideline-recommended care [21]. Consistent with these findings, in our study the proportion that had CKD-specific processes of care obtained in the year before recognition and after recognition increased for matched recognized and essentially stayed the same for unrecognized patients.
Our study is unique because in addition to looking at CKD-specific processes of care, we were able to study associations of EHR problem list documentation on important clinical outcomes such as development of ESRD and death. While we found a strong unadjusted association of increase ESRD risk among those with CKD recognition, with adjustment for potential confounders, the association declined and in the fully adjusted as well as proteinuria-sensitivity analysis no statistically significant relationship was found. We had hypothesized that having $\mathrm{CKD}$ recognition may lead to more co-management between primary care and specialists, more coordination of care perhaps leading to those patients having an arteriovenous fistula placed in a timely fashion before dialysis, preparation for dialysis, or better control of risk factors such as anemia, metabolic bone disease, and cardiovascular disease. While we were unable to capture in our dataset all the details of co-management, CKD recognition did not reduce ESRD rates in our study. Likewise, we found an unadjusted association of increased mortality risk with CKD recognition which was no longer significant in the fully adjusted models.

EHRs are here to stay and so it is essential to understand the importance of them in enhancing clinical practice in chronic disease over all [27] and specifically among the CKD population [28]. A proactive collaborative approach between specialty care and primary care for a CKD population in Hawaii led to more patients starting dialysis with arteriovenous fistulas and less referrals of low-risk CKD patients to nephrology [29]. While their intermediate outcomes did not change, an intervention at an urban Veteran's Affairs clinic provided education, academic detailing, and access to a CKD registry did show improvement in adherence to guideline-associated CKD processes of care [30]. It remains to be seen if tailored awareness to PCPs through use of quick reference guide, practice facilitation, and collaborative learning groups will make a difference $[31,32]$, but there is evidence that a chronic care or integrated patient-centered approach will work $[33,34]$.

This study has major strengths including many patients, a diverse population, and national database dialysis and mortality data for the study cohort. Nonetheless, there are important limitations. We were unable to account for or control for who entered CKD in the EHR problem list. Previous literature has suggested that PCPs are responsible for the majority of problem documentation in the EHR [35]. We attempted to control for many potential factors, however, as with all observational studies, we cannot account for residual confounding and true 
severity of illness. We had a relatively short follow-up time for the ESRD outcome (median of 1.9 years) and perhaps a longer follow-up time is needed to demonstrate the impact of changes in healthcare processes. As well, we are an open health system and cannot account for care that was obtained outside of our system which may account for some of the discrepancies in the pre- and postrecognition period. However, to attempt to minimize this, we limited our study to patients with at least 1 year follow-up in our health system and who had a Cleveland Clinic PCP listed in the EHR or had seen a Cleveland Clinic nephrologist up to 1 year after the confirmatory eGFR for CKD, yet some of the effects seen may be mediated by seeing a nephrologist. Likewise, how best to define CKD-specific performance measures and ultimately value in providing care to patients with CKD has not been established [36].

In summary, CKD recognition was low among our cohort of patients in a large EHR-based CKD registry and it was associated with lesser processes of care. We need to examine the long-term impact of CKD recognition and transition to dialysis. Further, we need to understand how to best increase CKD awareness, use patient-centered team-based approaches, use technology such as personalized health records and mobile applications to empower patients, and test clinical decision supports to help guide optimal CKD care. These will be important topics as we move to population management in the era of healthcare reform, and more are at risk and/or will have CKD.

\section{Acknowledgements}

Supported by National Institutes of Health (NIH) grants 1K23DK091363 (S.E.J.), RR024990 (S.D.N.), and R34DK094112 (J.V.N.). The creation of the registry was funded by an unrestricted grant from Amgen, Inc. to the Department of Nephrology and Hypertension Research and Education Fund.

\section{Disclosure Statement}

The authors have no conflicts of interest to disclose.

\section{References}

-1 Plantinga LC, Tuot DS, Powe NR: Awareness of chronic kidney disease among patients and providers. Adv Chronic Kidney Dis 2010;17: 225-236.

12 Coresh J, Selvin E, Stevens LA, et al: Prevalence of chronic kidney disease in the United States. JAMA 2007;298:2038-2047.

$\checkmark 3 \mathrm{~K} / \mathrm{DOQI}$ clinical practice guidelines for chronic kidney disease: evaluation, classification, and stratification. Am J Kidney Dis 2002; 39(suppl 1):S1-S266.

4 Beddhu S, Nigwekar SU, Ma X, Greene T: Associations of resting heart rate with insulin resistance, cardiovascular events and mortality in chronic kidney disease. Nephrol Dial Transplant 2009;24:2482-2488.

$\checkmark 5$ Go AS, Chertow GM, Fan D, McCulloch CE, Hsu CY: Chronic kidney disease and the risks of death, cardiovascular events, and hospitalization. N Engl J Med 2004;351:1296-1305.

$\checkmark 6$ Levey AS, Schoolwerth AC, Burrows NR, Williams DE, Stith KR, McClellan W: Comprehensive public health strategies for preventing the development, progression, and complications of CKD: report of an expert panel convened by the Centers for Disease Control and Prevention. Am J Kidney Dis 2009;53:522-535.

7 Levin A: Clinical epidemiology of cardiovascular disease in chronic kidney disease prior to dialysis. Semin Dial 2003;16:101-105.

$>8$ Parikh NI, Hwang SJ, Larson MG, Levy D, Fox CS: Chronic kidney disease as a predictor of cardiovascular disease (from the Framingham Heart Study). Am J Cardiol 2008;102: 47-53.

-9 Levey AS, Atkins R, Coresh J, et al: Chronickidney disease as a global public health problem: approaches and initiatives - a position statement from Kidney Disease Improving Global Outcomes. Kidney Int 2007;72:247-259.

10 Center for Medicare and Medicaid Services. EHR meaningful use overview. A federal government website managed by the Centers for Medicare \& Medicaid Services, 7500 Security Boulevard, Baltimore, MD 21244. https:// www.cms.gov/Regulations-and-Guidance/ Legislation/EHRIncentivePrograms/ Meaningful_Use.html. Last accessed February 9, 2013.

$>11$ Chaudhry B, Wang J, Wu S, et al: Systematic review: impact of health information technology on quality, efficiency, and costs of medical care. Ann Intern Med 2006; 144:742-752.

-12 Tang PC, Ralston M, Arrigotti MF, Qureshi L, Graham J: Comparison of methodologies for calculating quality measures based on administrative data versus clinical data from an electronic health record system: implications for performance measures. J Am Med Inform Assoc 2007; $14: 10-15$

13 Cebul RD, Love TE, Jain AK, Hebert CJ: Electronic health records and quality of diabetes care. N Engl J Med 2011;365:825-833.

14 Linder JA, Ma J, Bates DW, Middleton B, Stafford RS: Electronic health record use and the quality of ambulatory care in the United States. Arch Intern Med 2007;167:1400-1405.

15 Holbrook A, Pullenayegum E, Thabane L, et al: Shared electronic vascular risk decision support in primary care: Computerization of Medical Practices for the Enhancement of Therapeutic Effectiveness (COMPETE III) randomized trial. Arch Intern Med 2011;171: 1736-1744.

16 Romano MJ, Stafford RS: Electronic health records and clinical decision support systems: impact on national ambulatory care quality. Arch Intern Med 2011;171:897-903.

17 Black AD, Car J, Pagliari C, et al: The impact of eHealth on the quality and safety of health care: a systematic overview. PLoS Med 2011; 8:e1000387.

18 Navaneethan SD, Jolly SE, Schold JD, et al: Development and validation of an electronic health record-based chronic kidney disease registry. Clin J Am Soc Nephrol 2010;6:4049.

19 Bergstralh EJ, Kosanke JL: Computerized Matching of Cases to Controls. Technical Report Series No. 56. Mayo Clinic, Rochester, Minnesota, 1995; Available at http:// mayoresearch.mayo.edu/mayo/research/ biostat/upload/56.pdf.

20 Guessous I, McClellan W, Vupputuri S, Wasse $\mathrm{H}$ : Low documentation of chronic kidney disease among high-risk patients in a managed care population: a retrospective cohort study. BMC Nephrol 2009;10:25. 
21 Chase HS, Radhakrishnan J, Shirazian S, Rao MK, Vawdrey DK: Under-documentation of chronic kidney disease in the electronic health record in outpatients. J Am Med Inform Assoc 2010;17:588-594.

22 Allen AS, Forman JP, Orav EJ, Bates DW Denker BM, Sequist TD: Primary care management of chronic kidney disease. J Gen Intern Med 2010;26:386-392.

23 Plantinga LC, Tuot DS, Grubbs V, Hsu CY, Powe NR: Chronic kidney disease identification in a high-risk urban population: does automated eGFR reporting make a difference? J Urban Health 2012;89:965-976.

24 Rao MK, Morris CD, O’Malley JP, Davis MM, Mori M, Anderson S: Documentation and management of CKD in rural primary care. Clin J Am Soc Nephrol 2013;8:739-748.

25 Litvin CB, Nietert PJ, Wessell AM, Jenkins RG, Ornstein SM: Recognition and management of CKD in primary care. Am J Kidney Dis 2011;57:646-647.
26 Hartung DM, Hunt J, Siemienczuk J, Miller $\mathrm{H}$, Touchette DR: Clinical implications of an accurate problem list on heart failure treatment. J Gen Intern Med 2005;20:143-147.

-27 Dorr D, Bonner LM, Cohen AN, et al: Informatics systems to promote improved care for chronic illness: a literature review. J Am Med Inform Assoc 2007;14:156-163.

-28 Navaneethan SD, Jolly SE, Sharp J, et al: Elec tronic health records: a new tool to combat chronic kidney disease? Clin Nephrol 2013; 79:175-183.

29 Lee BJ, Forbes K: The role of specialists in managing the health of populations with chronic illness: the example of chronic kidney disease. BMJ 2009;339:b2395.

30 Drawz PE, Miller RT, Singh S, Watts B, Kern E: Impact of a chronic kidney disease registry and provider education on guideline adherence - a cluster randomized controlled trial. BMC Med Inform Decis Mak 2012;12:62.
31 Fox CH, Voleti V, Khan LS, Murray B, Vassalotti J: A quick guide to evidence-based chronic kidney disease care for the primary care physician. Postgrad Med 2008;120:E01E06.

32 Fox CH, Kahn LS, Vassalotti J: A decade after the KDOQI CKD guidelines: impact on primary care. Am J Kidney Dis 2012;60:707-709.

33 Narva AS, Sequist TD: Reducing health disparities in American Indians with chronic kidney disease. Semin Nephrol 2010;30:19-25.

34 Norfolk E, Hartle J: Nephrology care in a fully integrated care model: lessons from the Geisinger Health System. Clin J Am Soc Nephrol 2013;8:687-693.

35 Wright A, Feblowitz J, Maloney FL, Henkin S, Bates DW: Use of an electronic problem list by primary care providers and specialists. J Gen Intern Med 2012;27:968-973.

-36 Smith KA, Hayward RA: Performance measurement in chronic kidney disease. J Am Soc Nephrol 2011;22:225-234. 